\title{
Statin-Induced Changes in Mitochondrial Respiration in Blood Platelets in Rats and Human With Dyslipidemia
}

\author{
J. VEVERA ${ }^{1,2}$, Z. FIŠAR ${ }^{1}$, T. NEKOVÁŘOVÁ ${ }^{3,4,6}$, M. VRABLÍK ${ }^{5}$, L. ZLATOHLÁVEK ${ }^{5}$, \\ J. HROUDOVÁ ${ }^{1}$, N. SINGH ${ }^{1}$, J. RABOCH ${ }^{1}$, K. VALES $\check{S}^{3,6}$ \\ ${ }^{1}$ Department of Psychiatry, First Faculty of Medicine, Charles University in Prague and General \\ University Hospital in Prague, Prague, Czech Republic, ${ }^{2} 7^{\text {th }}$ Field Military Hospital, Hradec \\ Králové, Czech Republic, ${ }^{3}$ Institute of Physiology of the Czech Academy of Sciences, Prague, \\ Czech Republic, ${ }^{4}$ Department of Zoology, Ecology and Ethology Research Group, Faculty of \\ Science, Charles University in Prague, Prague, Czech Republic, ${ }^{5}{ }^{\text {rd }}$ Medical Department, First \\ Faculty of Medicine, Charles University in Prague and General University Hospital in Prague, \\ Prague, Czech Republic, ${ }^{6}$ National Institute of Mental Health, Klecany, Czech Republic
}

Received November 18, 2015

Accepted April 8, 2016

On-line July 15, 2016

\section{Summary}

3-hydroxy-3-methylglutaryl-coenzyme A (HMG-CoA) reductase inhibitors (statins) are widely used drugs for lowering blood lipid levels and preventing cardiovascular diseases. However, statins can have serious adverse effects, which may be related to development of mitochondrial dysfunctions. The aim of study was to demonstrate the in vivo effect of high and therapeutic doses of statins on mitochondrial respiration in blood platelets. Model approach was used in the study. Simvastatin was administered to rats at a high dose for 4 weeks. Humans were treated with therapeutic doses of rosuvastatin or atorvastatin for 6 weeks. Platelet mitochondrial respiration was measured using highresolution respirometry. In rats, a significantly lower physiological respiratory rate was found in intact platelets of simvastatintreated rats compared to controls. In humans, no significant changes in mitochondrial respiration were detected in intact platelets; however, decreased complex I-linked respiration was observed after statin treatment in permeabilized platelets. We propose that the small in vivo effect of statins on platelet energy metabolism can be attributed to drug effects on complex I of the electron transport system. Both intact and permeabilized platelets can be used as a readily available biological model to study changes in cellular energy metabolism in patients treated with statins.

\section{Key words}

Statin • Mitochondria • Platelet

\section{Corresponding author}

Z. Fišar, Department of Psychiatry, First Faculty of Medicine, Charles University in Prague and General University Hospital in Prague, Kateřinská 32, 12008 Prague, Czech Republic. E-mail: zfisar@If1.cuni.cz

\section{Introduction}

Statins, HMG-CoA (3-hydroxy-3-methylglutaryl-coenzyme A) reductase inhibitors, have been demonstrated to reduce all-cause mortality and the risk of major cardiovascular events among people without evidence of cardiovascular disease (Taylor et al. 2013). However, evidence has not yet been found regarding the benefit of statin therapy on all-cause mortality in the setting of high-risk primary prevention (Ray et al. 2010), elderly at high risk of cardiovascular disease (Lloyd et al. 2013), or women with coronary artery disease (Bukkapatnam et al. 2010). In addition to their beneficial cardiovascular effects, statins seem to have multiple noncardiovascular effects, which have not been sufficiently explored (Demierre et al. 2005, Vevera et al. 2005, Marzilli 2010, Gazzerro et al. 2012, Yu et al. 2013, 
Vevera et al. 2016). Adverse effects of statins include a significant increase in the risk of diabetes mellitus (Ruscica et al. 2014), transaminase elevation (Naci et al. 2013), and myotoxicity (Sathasivam 2012), including a modest increase in the risk of myositis; severe myopathy (rhabdomyolysis) is rare. Non-cardiovascular benefits of statins include reduced incidence of contrast nephropathy (Desai et al. 2014).

Several potential mechanisms have been proposed to explain both desirable and detrimental effects of statins on muscle tissue and the brain, including impairment of membranes, improved endothelial function, reduction in free radical production, and reduction of inflammation (Bifulco et al. 2008, António et al. 2014). Higher doses of some statins are associated with transaminase and creatine kinase elevations (Naci et al. 2013), which can affect cellular energetics.

Converging evidence supports a mitochondrial foundation for muscle, liver, and brain adverse effects associated with statins (Kaufmann et al. 2006, Nadanaciva et al. 2007, Golomb and Evans 2008, Galtier et al. 2012, Sirvent et al. 2012, Abdoli et al. 2013). Patients treated with statins showed impairment of mitochondrial respiration that mainly involves complex I of the respiratory chain. Decreased coenzyme $\mathrm{Q}_{10}$ content and decreased maximal capacity of mitochondrial oxidative phosphorylation have been reported in statintreated patients (Deichmann et al. 2010, Larsen et al. 2013, Vaughan et al. 2013). It seems that coenzyme $\mathrm{Q}_{10}$ improves the bioenergetics function of mitochondria treated with statins (Vaughan et al. 2013, MohammadiBardbori et al. 2015). On the other hand, statins also exert antioxidative effects, lower intramitochondrial ionized calcium, lower oxidative stress, prevent mitochondrial membrane permeability transition pore opening, and prevent the release of cytochrome $c$ from the mitochondria (Maes et al. 2012, Parihar et al. 2012, Zhao et al. 2015).

A high cholesterol level may increase the risk of developing Alzheimer's disease (Shepardson et al. 2011). Cholesterol lowering and mitochondrial effects of statins led to the assumption that statins could be useful in treatment or prevention of dementia. Novel drugs have been developed for the treatment of Alzheimer's disease that act on multiple targets, including cholinesterase activity, monoamine oxidase activity, $A \beta$ aggregation, $\gamma$-secretase activity, serotonin transporter activity, production of reactive oxygen species, calcium channels, mitochondrial permeability transition pores, and interactions of amyloid- $\beta$ with mitochondrial enzymes (Xie et al. 2006, Lim et al. 2011, Bolea et al. 2013). Statins also have been discussed as an alternative treatment approach in Alzheimer's disease (Kalra and Khan 2015). However, there is some controversy regarding the effect of statins on dementia: some studies have found beneficial effects, while other studies have not (Feldman et al. 2010, Padala et al. 2012, Valenti et al. 2014, Chatterjee et al. 2015). Recently, it was concluded that statins given late in life to people at risk of vascular disease and increased risk of vascular dementia or dementia due to Alzheimer's disease did not prevent cognitive decline or dementia (McGuinness et al. 2016). On the other hand, in randomized clinical trials, statin therapy was not associated with cognitive impairment (Ott et al. 2015).

Platelets are the cellular mediator of thrombosis, but they are also immune cells that initiate and accelerate many vascular inflammatory conditions (Morrell et al. 2014). Due to biochemical similarities between blood platelets and neurons, platelets have been established as a reliable model for the biochemical characterization of changes in brain neurons associated with mental disorders (Da Prada et al. 1988, Shad and Saeed 2007, Kaneez and Saeed 2009). Components of signaling pathways, with changes in platelets that are supposed to reflect changes in the brain, include serotonin receptors (Mendelson 2000), neurotransmitter transporters and storage vesicles (Mercado and Kilic 2010, Yubero-Lahoz et al. 2013), mitochondrial monoamine oxidase type B (Youdim 1988), brain derived neurotrophic factor (Pláteník et al. 2014), amyloid- $\beta$ (Chen et al. 1995), complexes of the mitochondrial respiratory chain (Bosetti et al. 2002, Cardoso et al. 2004, Valla et al. 2006), and a number of blood-based biomarkers (Casoli et al. 2013, Donovan et al. 2013).

High-resolution respirometry (Gnaiger et al. 2000, Pesta and Gnaiger 2012) represents a sensitive technique to determine small mitochondrial dysfunctions. Studies examining mitochondrial function are typically measured in permeabilized skeletal muscle fibers. However, platelet mitochondria have been established as well suited for ex vivo analysis of cellular respiration (Sjövall et al. 2010, 2013, Hroudová et al. 2013) and the activity of respiratory chain complexes (Böhm et al. 2007). Platelets are an easily obtainable source of viable mitochondria and disturbances in the function of platelet mitochondria have been demonstrated in aging (Merlo Pich et al. 1996, Lenaz et al. 2000, Xu et al. 2007) and in 
variety of diseases, including neurodegenerative disorders (Krige et al. 1992, Hauptmann et al. 2006, Shi et al. 2008, Hroudová et al. 2013, Fišar et al. 2016).

We suggest that intact and/or permeabilized platelets might serve as an appropriate and easy available biological model for studying energetic metabolism in statin-treated patients. The aim of our study was to demonstrate the effect of short-term (several weeks) statin application on mitochondrial respiration in human and rat platelets. Simvastatin-treated rats were compared to controls receiving vehicle jelly without simvastatin. In humans, mitochondrial respiration in blood platelets was compared before and after statin treatment in patients with disorders of lipoprotein metabolism; specifically, in subjects not contraindicated for statin use.

\section{Materials and Methods}

\section{Chemicals and solutions}

Mitochondrial respiration in intact platelets was measured in plasma diluted with inorganic Krebs and Henseleit isotonic medium $(118 \mathrm{mM} \mathrm{NaCl}, 4.7 \mathrm{mM} \mathrm{KCl}$, $1.2 \mathrm{mM} \quad \mathrm{KH}_{2} \mathrm{PO}_{4}, \quad 1.2 \mathrm{mM} \quad \mathrm{MgSO}_{4} .7 \mathrm{H}_{2} \mathrm{O}, \quad 25 \mathrm{mM}$ $\mathrm{NaHCO}_{3}$, and $11.1 \mathrm{mM}$ glucose; $\mathrm{pH}$ 7.4). Mitochondrial respiration medium (MiR05) used in assays with permeabilized platelets consisted of $110 \mathrm{mM}$ sucrose, $60 \mathrm{mM} \quad \mathrm{K}^{+}$-lactobionate, $20 \mathrm{mM}$ taurine, $3 \mathrm{mM}$ $\mathrm{MgCl}_{2} \cdot 6 \mathrm{H}_{2} \mathrm{O}, \quad 10 \mathrm{mM} \quad \mathrm{KH}_{2} \mathrm{PO}_{4}, \quad 0.5 \mathrm{mM} \quad$ EGTA, $1 \mathrm{~g} / \mathrm{l} \mathrm{BSA}$ essentially fatty acid free, and $20 \mathrm{mM}$ HEPES, adjusted to $\mathrm{pH} 7.1$ with $\mathrm{KOH}$ (Gnaiger et al. 2000, Pesta and Gnaiger 2012).

Stock solutions used for platelet oxygen consumption rate measurements included $10 \mathrm{mg} / \mathrm{ml}$ digitonin, $2 \mathrm{M}$ malate, $2 \mathrm{M}$ pyruvate, $0.5 \mathrm{M}$ ADP, $2 \mathrm{M}$ glutamate, $1 \mathrm{M}$ succinate, $4 \mathrm{mg} / \mathrm{ml}$ oligomycin, $1 \mathrm{mM}$ or $10 \mathrm{mM}$ carbonyl cyanide $p$-trifluoromethoxyphenylhydrazone (FCCP), $1 \mathrm{mM}$ rotenone, and $0.5 \mathrm{mg} / \mathrm{ml}$ antimycin A. All the chemicals were purchased from Sigma-Aldrich Co. (St. Louis, MO, USA).

\section{High-resolution respirometry}

High-resolution respirometry measures electron transfer in the electron transport system (ETS) quantified by the oxygen consumption rate. An OROBOROS Oxygraph-2k (O2k; OROBOROS INSTRUMENTS, Austria) was used. Samples, with a volume of $2 \mathrm{ml}$, were measured in two glass chambers equipped with Clark polarographic oxygen electrodes. Common experimental conditions include a physiological temperature of $37^{\circ} \mathrm{C}$, stirring at $750 \mathrm{rpm}$, a closed-chamber mode of operation, calibration of the polarographic oxygen sensor before each measurement, and periodic measurement of instrumental background oxygen consumption (Gnaiger 2014).

The OROBOROS Oxygraph-2k represents a sensitive instrument used for analysis of mitochondrial respiration in research of cellular bioenergetics during physiological or pathophysiological processes, as well as for studying the effects of different drugs. Measurements were carried out on one set of 6 patients and 6 control and 6 experimental rats. Excellent measurement sensitivity and stability enabled us to obtain valid results even from these small sample sets.

\section{Platelet preparation}

Viable platelets are easily available components of peripheral blood, which may be useful for in situ studies of mitochondrial respiration (Sjövall et al. 2010, 2013, Hroudová et al. 2013). Thus, we used platelets as a biological model to analyze statin-induced changes in mitochondrial respiration under physiological conditions.

Six patients (4 males and 2 females, age of $43.7 \pm 14.3$ years) with primary hypercholesterolemia (who were monitored at the Lipid Clinic of the $3^{\text {rd }}$ Dept. of Medicine at Charles University in Prague, and were indicated for statin treatment) were enrolled in the study. Blood samples were collected at baseline (without any lipid lowering pharmacotherapy) and again after 6 weeks of treatment with rosuvastatin ( 5 patients) or atorvastatin (1 patient) at a dosage $0.2-0.5 \mathrm{mg} / \mathrm{kg}$ per day. Study participants characteristics at baseline and follow up are presented in Table 1. Two of the study participants were smokers, two had arterial hypertension, none had diabetes. Their transaminase levels and creatine phosphokinase activity were normal. Average body mass index was $24.8 \pm 2.6 \mathrm{~kg} / \mathrm{m}^{2}$ and did not change during the study.

Between 7:00 and 8:00 AM, peripheral blood samples were drawn from the antecubital vein of each fasting participant via BD Vacutainer ${ }^{\circledR}$ blood collection tubes (Becton, Dickinson and Company, Franklin Lakes, NJ 07417 USA), with $\mathrm{K}_{2}$ EDTA as the anticoagulant. The study was carried out according to the principles expressed in the Declaration of Helsinki and the study protocol was approved by the Ethic Review Board of the First Faculty of Medicine and the General University Hospital in Prague, Czech Republic. 
Table 1. Characteristics of study participants at baseline and after 6 weeks of statin treatment $(\mathrm{N}=6)$.

\begin{tabular}{|c|c|c|c|c|c|c|c|c|c|c|c|c|c|c|}
\hline No & $\begin{array}{c}\text { Age } \\
\text { (years) }\end{array}$ & Gender & $\begin{array}{l}\text { Chol 1 } \\
(\mathrm{mM})\end{array}$ & $\begin{array}{l}\text { Chol } 2 \\
(\mathrm{mM})\end{array}$ & $\begin{array}{l}\text { TG } 1 \\
(\mathrm{mM})\end{array}$ & $\begin{array}{l}\text { TG } 2 \\
(\mathrm{mM})\end{array}$ & $\begin{array}{l}\text { HDL } 1 \\
(\mathrm{mM})\end{array}$ & $\begin{array}{l}\text { HDL } 2 \\
(\mathrm{mM})\end{array}$ & $\begin{array}{l}\text { LDL } 1 \\
(\mathrm{mM})\end{array}$ & $\begin{array}{l}\text { LDL } 2 \\
(\mathrm{mM})\end{array}$ & $\begin{array}{l}\text { Glu 1 } \\
(\mathrm{mM})\end{array}$ & $\begin{array}{l}\text { Glu } 2 \\
\text { (mM) }\end{array}$ & $\begin{array}{c}\text { BMI 1 } \\
\left(\mathrm{kg} / \mathrm{m}^{2}\right)\end{array}$ & $\begin{array}{l}\text { Treatment } \\
\text { (dose) }\end{array}$ \\
\hline 1 & 61 & $\mathrm{f}$ & 8.12 & 5.01 & 2.88 & 1.54 & 1.44 & 1.42 & 5.38 & 2.90 & 5.80 & 6.30 & 25.3 & $\begin{array}{l}\text { Rosuvastatin } \\
\quad(10 \mathrm{mg})\end{array}$ \\
\hline 2 & 35 & $\mathrm{~m}$ & 6.35 & 5.01 & 1.48 & 1.19 & 1.24 & 1.39 & 4.44 & 3.08 & 4.60 & 4.80 & 24.8 & $\begin{array}{l}\text { Rosuvastatin } \\
\quad(40 \mathrm{mg})\end{array}$ \\
\hline 3 & 34 & $\mathrm{~m}$ & 7.74 & 5.61 & 2.07 & 1.65 & 1.57 & 1.29 & 5.24 & 3.58 & 5.00 & 5.10 & 25.8 & $\begin{array}{l}\text { Rosuvastatin } \\
\quad(20 \mathrm{~g})\end{array}$ \\
\hline 4 & 51 & $\mathrm{~m}$ & 8.34 & 5.28 & 0.78 & 0.85 & 1.81 & 1.71 & 6.18 & 3.19 & 4.90 & 5.10 & 27.0 & $\begin{array}{l}\text { Rosuvastatin } \\
\quad(40 \mathrm{mg})\end{array}$ \\
\hline 5 & 22 & $\mathrm{f}$ & 10.20 & 5.90 & 2.67 & 1.43 & 1.96 & 1.70 & 7.05 & 3.56 & 4.60 & 4.40 & 19.3 & $\begin{array}{l}\text { Rosuvastatin } \\
\quad(20 \mathrm{mg})\end{array}$ \\
\hline 6 & 59 & $\mathrm{~m}$ & 6.12 & 4.95 & 1.04 & 1.23 & 1.41 & 1.33 & 4.24 & 3.07 & 4.30 & 5.20 & 26.7 & $\begin{array}{l}\text { Atorvastatin } \\
\quad(10 \mathrm{mg})\end{array}$ \\
\hline Mean & 43.7 & & 7.81 & *5.29 & 1.82 & 1.32 & 1.57 & 1.47 & 5.42 & $* 3.23$ & 4.87 & 5.15 & 24.8 & \\
\hline SD & 14.3 & & 1.36 & 0.35 & 0.79 & 0.26 & 0.25 & 0.17 & 0.97 & 0.25 & 0.47 & 0.58 & 2.6 & \\
\hline
\end{tabular}

Abbreviations: Index 1, baseline values; Index 2, post-treatment values; Chol, cholesterol; TG, triglycerides; HDL, high density lipoprotein cholesterol; LDL, low density lipoprotein cholesterol; Glu, fasting glucose concentration; BMI, body mass index Significantly different mean values observed when values were compared before and after treatment (using the Wilcoxon signed-rank test) are marked: $* P<0.05$.

The experimental animals were adult naive male Long-Evans rats that were 3-month-old at the beginning of the experiment. Simvastatin (Simvastatin Mylan), dissolved in sweetened jelly, was administered at a dosage of $30 \mathrm{mg} / \mathrm{kg}$ per day for four weeks. The animals were randomly assigned to an experimental group of 6 rats receiving vehicle jelly with simvastatin and a control group of 6 rats receiving vehicle jelly alone. On day 28 of treatment, the animals were sacrificed by decapitation and blood samples were collected with $\mathrm{K}_{2}$ EDTA as the anticoagulant. All procedures were done in accordance with the Animal Protection Code of the Czech Republic and the European Council directives (2010/63/EC; $86 / 609 /$ EEC). The study protocol was approved by the Animal Care Committee of the Institute of Physiology of Academy of Sciences of the Czech Republic.

Whole non-coagulable blood underwent centrifugation at $200 \mathrm{~g}$ for $20 \mathrm{~min}$ at $25^{\circ} \mathrm{C}$ to separate a platelet rich plasma (PRP) aliquot from the red blood cells. The upper portion of the centrifuged samples, which contained the platelets dissolved in plasma, was drawn off, and the platelets were counted using a microscope and a counting chamber. The platelets in the plasma samples were used to measure mitochondrial respiration in intact platelets. Mitochondrial respiration in permeabilized platelets was measured in diluted PRP (Franco et al. 2012). Plasma samples containing platelets were centrifuged at $1500 \mathrm{~g}$ for $10 \mathrm{~min}$ at $25{ }^{\circ} \mathrm{C}$. The plasma was then discarded and the pellet was resuspended in the same volume of MiR05.

\section{Experimental protocols}

Experimental protocols for intact or permeabilized platelets were adapted from Sjövall et al. $(2010,2013)$ as described previously (Hroudová et al. 2013).

Respiration of intact platelets with endogenous mitochondrial substrates was measured in PRP diluted (1:1) with Krebs and Henseleit isotonic medium. Endogenous basal rates of platelet respiration (resting state respiration, physiological respiration, $P R$ ) were measured without any additives. Respiration that was independent of adenosine diphosphate (ADP) phosphorylation (LEAK) was measured after the addition of $2 \mu \mathrm{g} / \mathrm{ml}$ oligomycin (an ATP synthase inhibitor). The maximal capacity of the electron transport system (ETSC) in the non-coupled state was achieved by titration with the protonophore carbonyl cyanide $p$-trifluoro-methoxyphenylhydrazone (FCCP), in a range from 5 to $50 \mu \mathrm{M}$. Finally, mitochondrial respiration was inhibited using $2.5 \mu \mathrm{M}$ of the complex I inhibitor, rotenone (Rot) and $2.5 \mu \mathrm{g} / \mathrm{ml}$ of antimycin A (a complex III inhibitor); residual oxygen consumption $(R O X)$ was measured so that it could be subtracted from all other mitochondrial respiratory rates.

Respiration of permeabilized platelets was measured in washed (plasma free) platelets, whose plasma membranes were permeabilized using digitonin $(50 \mu \mathrm{g} / \mathrm{ml})$. Subsequently, substrates were added for complex I- and complex I+II-linked respiration. ADP stimulated respiration $(A D P)$ was measured after the addition of $5 \mathrm{mM}$ malate, $5 \mathrm{mM}$ pyruvate, $1 \mathrm{mM}$ ADP, and $5 \mathrm{mM}$ glutamate. Respiratory capacity at saturating 
concentrations of ADP, inorganic phosphate, oxygen, and defined complex I+II-linked substrates (OXPHOS capacity) was measured after the addition of $10 \mathrm{mM}$ succinate. A non-phosphorylating resting state of intrinsic uncoupled or decoupled respiration ( $L E A K)$ was induced using $2 \mu \mathrm{g} / \mathrm{ml}$ oligomycin. Maximal convergent capacity of the ETS (ETSC) was obtained by titration with the uncoupling agent FCCP in each experiment (range 1 to $4 \mu \mathrm{M})$. Complex I-supported respiration was inhibited using $0.5 \mu \mathrm{M}$ rotenone (Rot). Finally, $1.25 \mu \mathrm{g} / \mathrm{ml}$ antimycin A was added and residual oxygen consumption $(R O X)$ was measured for subtraction from all other mitochondrial respiratory rates.

\section{Data analysis}

The respirometry data were collected and analyzed using DatLab 4.3 software (Oroboros Instruments, Innsbruck, Austria). Platelet oxygen consumption rates (platelet respiratory rate, $\mathrm{O}_{2}$ flow per cell) were normalized for either platelet concentration (and expressed as pmol $\mathrm{O}_{2}$ consumed per second relative to $10^{6}$ platelets) or maximum oxygen flux in uncoupled respiration (and expressed as a control ratio in relative units). Net physiological respiration (NetPR) in intact platelets was calculated as the difference $P R-L E A K$. Statistical analyses were performed using Statistica (version 12, StatSoft, Inc., Tulsa, OK, USA). Data are expressed as arithmetic means. Standard deviations (SD) were calculated to characterize group variability. Hypothesis testing was performed using the MannWhitney $U$ test and Wilcoxon signed-rank test.

\section{Results}

Effect of simvastatin on mitochondrial respiration in intact rat platelets

Mitochondrial respiration in intact blood platelets was measured, after 4 weeks of treatment, in a total of 6 control rats and 6 rats treated with simvastatin. The flux control ratio LEAK/ETSC in intact platelets was found to be $0.079 \pm 0.027$ (mean $\pm \mathrm{SD}$, $\mathrm{N}=12$ ) (Fig. 1B), which indicates the functional integrity of the inner mitochondrial membrane.

Mean mitochondrial oxygen consumption rates normalized for platelet concentration were measured before $(P R)$ and after inhibition of ADP phosphorylation by oligomycin $(L E A K)$, after uncoupling by FCCP (ETSC), and after inhibition of complex I-linked respiration by rotenone (Rot) (Fig. 1A). Control ratios were calculated as ratios of platelet oxygen consumption rates at different respiratory states to ETSC (Fig. 1B).
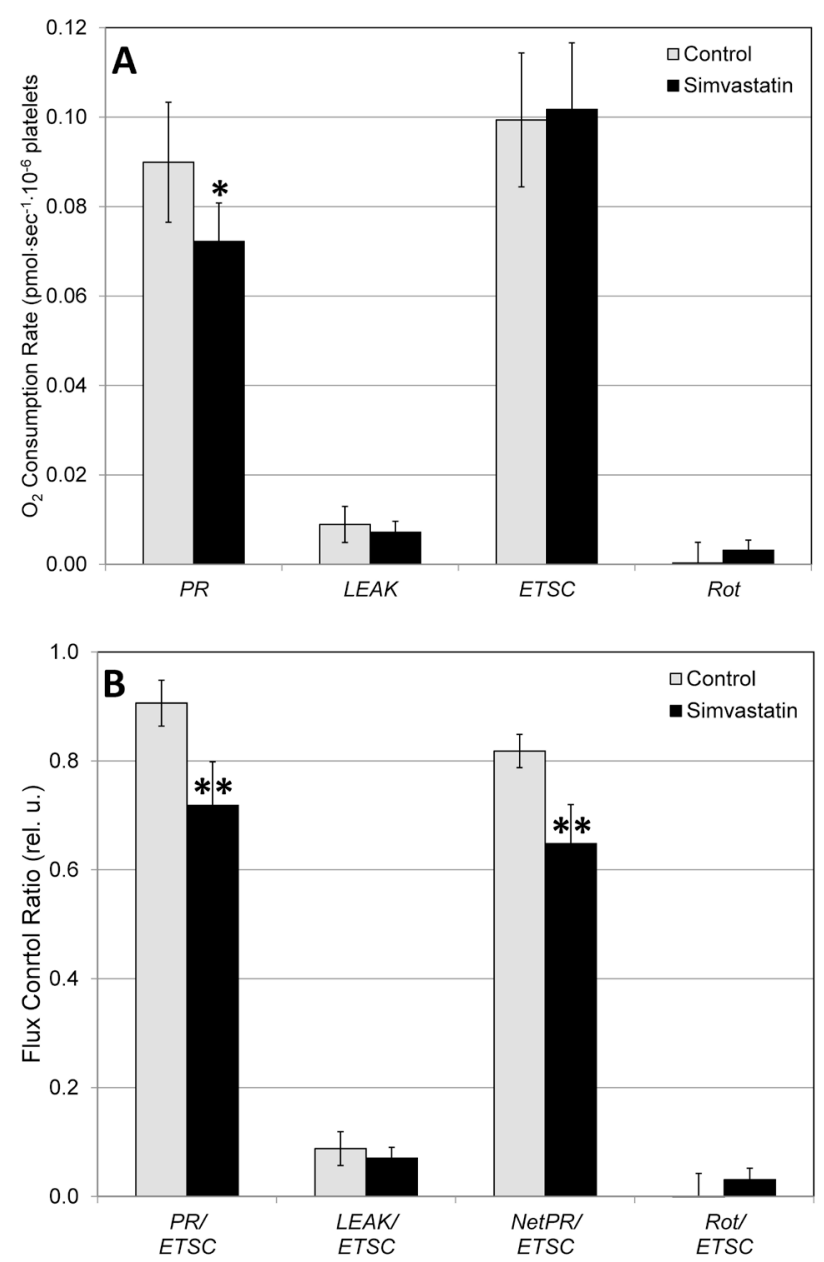

Fig. 1. Mitochondrial respiration in intact platelets of simvastatintreated rats after 4 weeks of treatment. Platelet respiratory rates were normalized for (A) platelet concentration and (B) maximal capacity of the electron transport system (ETSC). Mean \pm standard deviations are shown. Significantly different mean values found when compared with controls (using the MannWhitney $\mathrm{U}$ test) are marked: $* P<0.05, * * P<0.01$.

Abbreviations: ETSC, the maximal capacity of the electron transport system in the non-coupled state was achieved by titration with protonophore FCCP (carbonyl cyanide $p$-trifluoromethoxyphenylhydrazone); $L E A K$, respiration that was independent of adenosine diphosphate phosphorylation was measured after the addition of oligomycin; NetPR, net physiological respiration was calculated as the difference $P R$ $\angle E A K ; P R$, endogenous basal rate of platelet respiration (physiological respiration); Rot, mitochondrial respiration after the addition of rotenone.

The endogenous basal rate of platelet respiration $(P R)$ was significantly decreased in simvastatin-treated rats compared with controls $(P=0.045)$ (Fig. 1A). The flux control ratio was significantly decreased for both PR/ETSC $(P=0.0082)$ and NetPR/ETSC $(P=0.005)$ in simvastatin-treated rats (Fig. 1B); a decrease in $P R$ was 
responsible for this effect.

Effect of statins on mitochondrial respiration in human platelets

Mitochondrial respiration in both intact and permeabilized platelets was measured in 6 patients before and after 6 weeks of treatment with a statin. The flux control ratio $L E A K / E T S C$ was found to be $0.076 \pm 0.046$ (mean $\pm \mathrm{SD}, \mathrm{N}=12$ ) in intact platelets (Fig. 2B) and
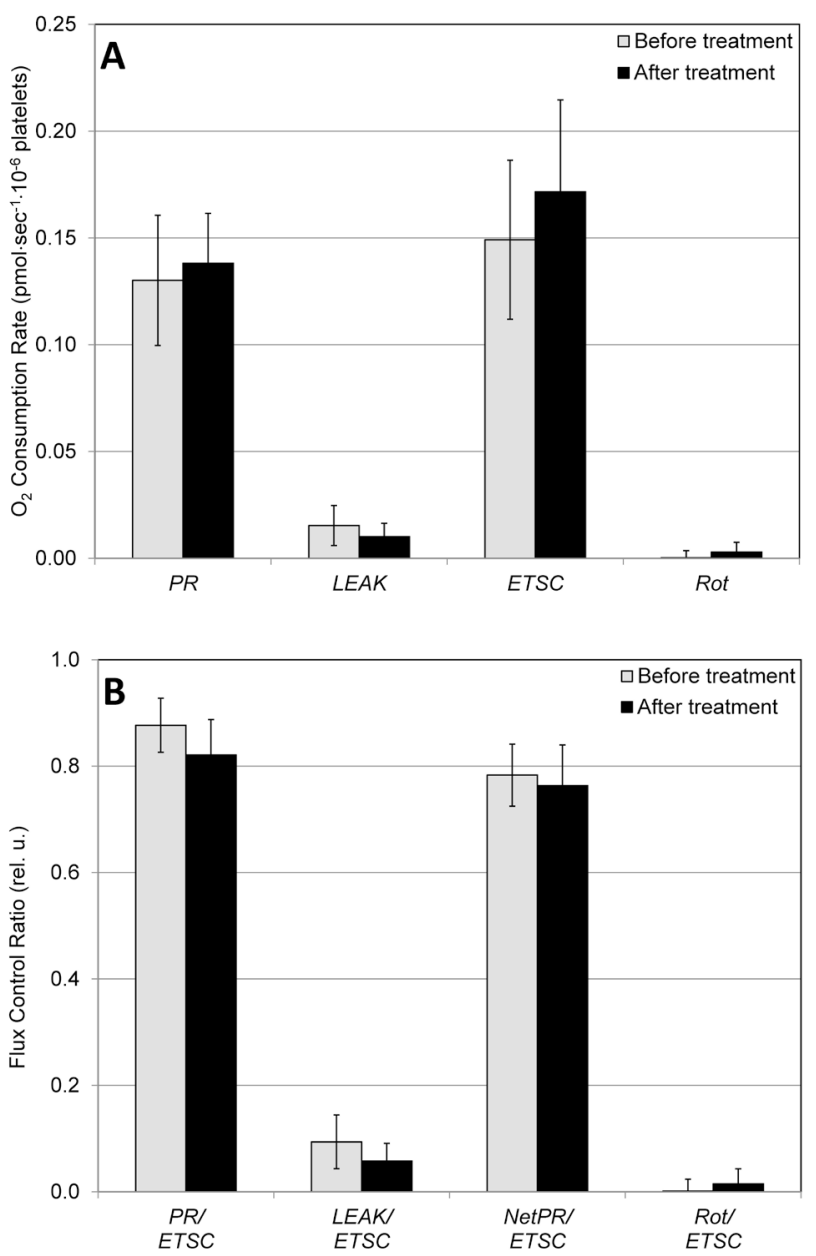

Fig. 2. Mitochondrial respiration in intact platelets of statintreated humans before treatment and after 6 weeks of treatment. Platelet respiratory rates were normalized for (A) platelet concentration and (B) maximal capacity of the electron transport system (ETSC). Mean \pm standard deviations are shown. No significant differences between before and after treatment mean values were found (using the Wilcoxon signed-rank test). Abbreviations: ETSC, the maximal capacity of the electron transport system in the non-coupled state was achieved by titration with protonophore FCCP (carbonyl cyanide $p$-trifluoromethoxyphenylhydrazone); $\angle E A K$, respiration that was independent of adenosine diphosphate phosphorylation was measured after the addition of oligomycin; NetPR, net physiological respiration was calculated as the difference $P R$ $L E A K ; P R$, endogenous basal rate of platelet respiration (physiological respiration); Rot, mitochondrial respiration after the addition of rotenone.
$0.145 \pm 0.024$ (mean $\pm \mathrm{SD}, \mathrm{N}=12$ ) in permeabilized platelets (Fig. 3B), which indicates the functional integrity of the inner mitochondrial membrane.

Mean mitochondrial oxygen consumption rates, normalized for platelet concentrations, are summarized in Figures $2 \mathrm{~A}$ and $3 \mathrm{~A}$. Control ratios, calculated as oxygen consumption rates normalized to ETSC, are displayed in Figures $2 \mathrm{~B}$ and $3 \mathrm{~B}$. No significant changes in mitochondrial respiration were detected in intact platelets (Fig. 2).
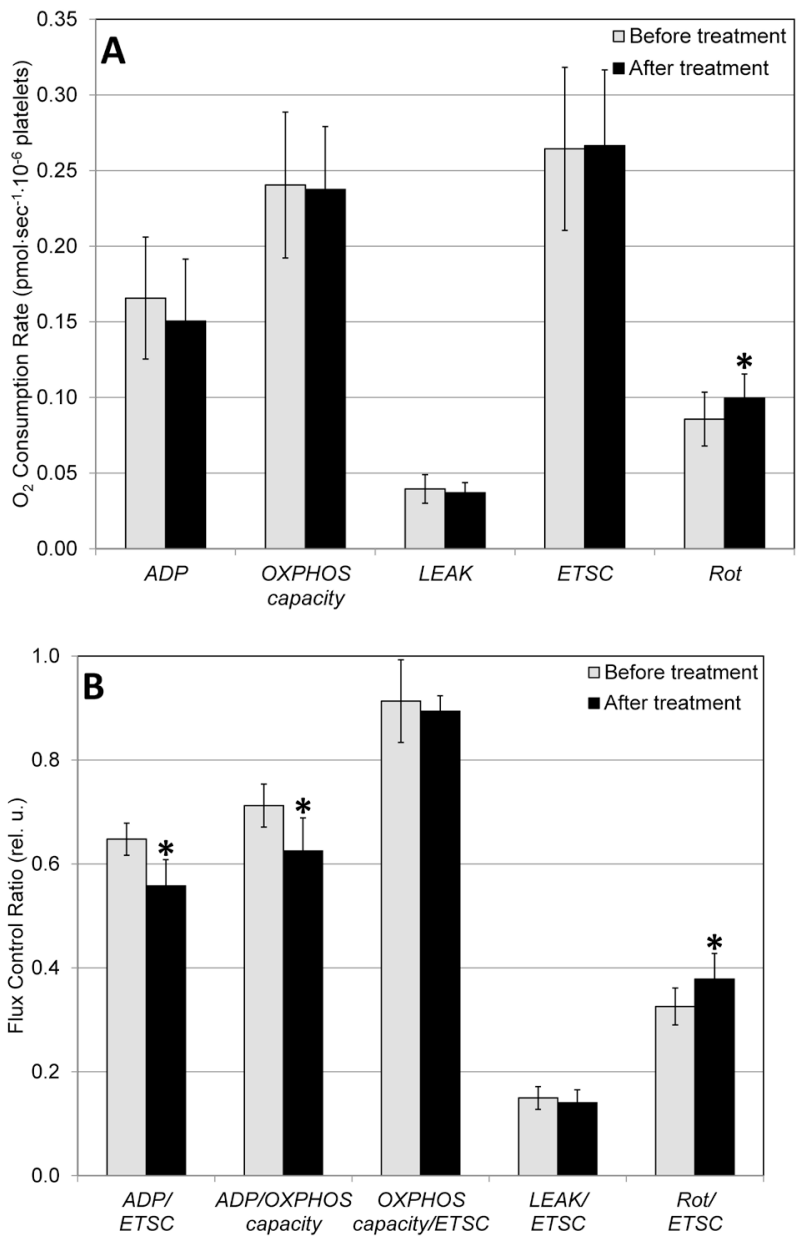

Fig. 3. Mitochondrial respiration in permeabilized platelets of statin-treated humans before treatment and after 6 weeks of treatment. Platelet respiratory rates were normalized for (A) platelet concentration and (B) maximal capacity of the electron transport system (ETSC) or maximal coupled oxidative capacity (OXPHOS capacity). Mean \pm standard deviations are shown. Significantly different mean values found when comparing values before and after treatment (using the Wilcoxon signed-rank test) are marked: * $P<0.05$. Abbreviations: $A D P$, adenosine diphosphate stimulated respiration; ETSC, the maximal capacity of the electron transport system in the non-coupled state was achieved by titration using the protonophore FCCP (carbonyl cyanide $p$-trifluoromethoxyphenylhydrazone); $L E A K$, respiration that was independent of ADP phosphorylation was measured after the addition of oligomycin; OXPHOS capacity, respiratory capacity at saturating concentrations of ADP, inorganic phosphate, oxygen, malate, pyruvate, glutamate, and succinate; $R o t$, mitochondrial respiration after the addition of rotenone. 
In permeabilized platelets, the OXPHOS capacity/LEAK ratio was found to be $6.36 \pm 0.89$ (mean $\pm \mathrm{SD}, \mathrm{N}=12$ ), which indicated good coupling of electron transport to ATP synthesis and was comparable to previous results (Sjöval et al. 2013). No change was observed during treatment with statins. The rotenoneinduced decrease of the oxygen consumption rate was significantly lower after treatment with statins (Fig. 3A). A significant statin-induced decrease in ADP stimulated respiration (in the presence of substrates supporting respiration through complex I) was observed when the platelet respiration rate was normalized for maximal uncoupled capacity ETSC $(P=0.027)$ as well as for maximal coupled oxidative capacity $O X P H O S$ capacity $(P=0.046)$; higher oxygen consumption rates after rotenone addition were also observed (Fig. 3B). These results indicate significantly decreased complex I-linked respiration after statin treatment.

\section{Discussion}

The respiratory rate of platelets may serve as an easily available biological marker for an in situ study of disease-related or drug-induced changes in mitochondrial function (Sjövall et al. 2010, 2013; Hroudová et al. 2013). Previous studies dealing with statin-induced in vivo changes in mitochondrial functions have been performed mostly on skeletal muscle mitochondria. The current pilot study is the first, as far as we know, to examine the effects of statins on the mitochondrial respiratory rate in intact blood platelets dissolved in plasma without any additives, i.e. when platelet respiratory rates are measured at the resting state respiration at or near physiological conditions.

Lowering of the physiological respiratory rate in intact platelets (Fig. 1A), as well as a decrease in the control ratio representing respiratory efficiency in simvastatin-treated rats (Fig. 1B), are in agreement with recently published in vitro inhibitory effects of simvastatin on phosphorylating respiration in permeabilized skeletal muscle fibers (La Guardia et al. 2013, Larsen et al. 2013). However, we did not find inhibition of uncoupled respiration associated with simvastatin (Fig. 1A). Physiological respiration, but not ETS capacity was observed to be affected by 4 weeks of simvastatin administration. This indicates that modulation upstream of mitochondrial metabolism and/or ATP synthase activity may participate in the in vivo effect of simvastatin on platelet respiratory rates. However, the effects of simvastatin on mitochondrial respiration in rat platelets are apparently linked to administration of high doses of simvastatin.

Pleiotropic effects of statins are frequently studied in vitro and in experiments on animal models, when the plasma concentrations of statins are much higher than those achieved during therapeutic use in humans (Björkhem-Bergman et al. 2011). To induce a similar effect in rats, we used simvastatin at a dosage of $30 \mathrm{mg} / \mathrm{kg}$ per day for 4 weeks. The effect of high doses of statins on mitochondrial respiration in intact platelets of rats (Fig. 1) was not present in human platelets at therapeutic statin doses (Fig. 2). We suggest that the observed differences between mitochondrial respiration in rat and human intact platelets (suspended in plasma) can be attributed to differences in plasma concentration of statins.

There is strong evidence that statins, as a class, are generally safe and adverse events associated with statin therapy are uncommon (Naci et al. 2013). However, the highest potency statins (rosuvastatin and atorvastatin) have shown higher muscle adverse event rates (Hoffman et al. 2012). We studied the effect of treatment with these newer statins on mitochondrial respiration in relatively young hyperlipidemic subjects who were not contraindicated for statin use (i.e. they were not selected for increased risk for problems on statins). The lipophilic or hydrophilic nature of statins seems to play an important role in the occurrence of side effects, with lovastatin and simvastatin being the most lipophilic, followed by atorvastatin, fluvastatin, rosuvastatin, and pravastatin. We did not observe any difference in mitochondrial respiration in platelets of patients treated with rosuvastatin and atorvastatin. Thus, mean values of respiratory parameters were calculated for the group of patients treated with rosuvastatin or atorvastatin as a whole. Disturbing effects on platelet mitochondrial respiration seem to be very low at therapeutic doses of atorvastatin and rosuvastatin, with no significant statininduced changes in mitochondrial respiration being observed in intact human platelets (Fig. 2). Additionally, relatively little change in complex I-linked respiration was seen in permeabilized platelets (Fig. 3). This is consistent with the observation of a low incidence of clinically significant side effects associated with statin therapy. Our results do not support the claims of statinrelated mitochondrial toxicity that have been predicted on the basis of in vitro experiments; such claims fail to appreciate the potential neuroprotective efficacy of statins 
(Parihar et al. 2012, Malfitano et al. 2014, Li et al. 2014), which could be useful in the treatment of various neurological and neuropsychiatric disorders.

Limitations of this study include the following facts: the sample size was small, patients were not selected for a risk of having statin-induced problems, and the duration of treatment was short, relative to the time needed to develop potential statin problems. Our measurements after a few weeks of statin administration, in hyperlipidemic subjects without a significant risk of statin-induced problems, was unable to detect any risk of adverse effects that could be associated with long-term administration of statins. However, this study was designed as a pilot study to determine whether the respiration rate of mitochondria in intact or permeabilized platelets is impaired by therapeutic (in humans) or high doses (in rats) of statins. The results must be interpreted with caution, but we suggest that the data are sufficient to indicate that mitochondrial respiration in intact platelets is not significantly changed after short-term treatment at therapeutic statin doses; however, high doses of simvastatin, in rats, can induce a significant decrease in mitochondrial resting state respiration even after shortterm applications. The results may be useful for the design of further studies of in vivo effects of statins on platelet mitochondrial respiration in people with established mitochondrial pathology, and in people with risk factors for mitochondria related problems. We hope our study will be the first step towards experiments designed to detect (using measurements of mitochondrial respiration in platelets) the risk of development of certain statin-induced adverse effects.

There is no expectation that everyone placed on statins will suffer adverse effects due to mitochondrial toxicity. However, it can be expected that mitochondrial function will be affected while achieving higher levels of statins in the blood, though this may not always be clinically manifested. In this pilot study, we wanted to determine whether such changes of mitochondrial function occur after short-term administration of statins, regardless of whether significant adverse effects from long-term administration of statins are produced or not. It can be expected that mitochondrial function will be affected while achieving higher concentrations of statins in the blood, even though it may not clinically manifest.

Mitochondrial respiration is a very complex system with many feedbacks. Our results suggest that statin-induced changes in the activity of respiratory chain complexes (described in earlier in vitro experiments) are either very small or are compensated for in intact platelets. We assume that the measurement of mitochondrial respiration in permeabilized platelets (with an excess supply of substrates and inhibitors) may reveal some drug-induced changes, which are hidden in intact platelets. Our measurement of respiration in permeabilized human platelets revealed that short-term administration of statins may slightly disrupt complex Ilinked respiration; however, it does not cause a significant disruption in the physiological respiration in intact platelets.

\section{Conclusions}

The results of our study demonstrate decreased respiratory rates in intact platelets with unchanged respiratory capacity after short-term treatment with high doses of simvastatin in rats. Assuming that platelet respiration mirrors mitochondrial respiration in other cells, treatment with high doses of statins may disturb cellular bioenergetics in the organs most sensitive to ATP insufficiency, which might be related to its adverse effects. At therapeutic doses in humans, we did not observe a significant effect of statins on mitochondrial respiration in intact platelets. The reduction in complex I-linked respiration observed in permeabilized platelets shows small (in vivo compensated) disruptions in respiratory chain function even at therapeutic doses of statins. We suggest that platelets might be used as an easily available biological model to study the effects of statins on mitochondrial functions with a minimal burden on patients.

\section{Conflict of Interest}

There is no conflict of interest.

\section{Acknowledgements}

This research was supported by projects PRVOUKP26/LF1/4 and P34 from Charles University in Prague, Czech Republic; grants NT/1448, NT13386, NT134034/2012, and AZV 15-28967A and AZV 15-28277A provided by the Ministry of Health of the Czech Republic; Czech Science Foundation grants P304/12/G069 and P303/12/1464; project "National Institute of Mental Health (NIMH-CZ)" - grant number ED2.1.00/03.0078 of the ERDF; AV CR M200111204; and RVO: 67985823. The authors thank Zdeněk Hanuš and Michaela Fialová for providing technical assistance. 


\section{References}

ABDOLI N, HEIDARI R, AZARMI Y, EGHBAL MA: Mechanisms of the statins cytotoxicity in freshly isolated rat hepatocytes. J Biochem Mol Toxicol 27: 287-294, 2013.

ANTÓNIO N, SOARES A, FERNANDES R, SOARES F, LOPES A, CARVALHEIRO T, PAIVA A, PROVIDÊNCIA LA, GONÇALVES L, FONTES RIBEIRO C: Endothelial progenitor cells in diabetic patients with myocardial infarction - can statins improve their function? Eur J Pharmacol 741: 25-36, 2014.

BIFULCO M, MALFITANO AM, MARASCO G: Potential therapeutic role of statins in neurological disorders. Expert Rev Neurother 8: 827-837, 2008.

BJÖRKHEM-BERGMAN L, LINDH JD, BERGMAN P: What is a relevant statin concentration in cell experiments claiming pleiotropic effects? Br J Clin Pharmacol 72: 164-165, 2011.

BÖHM M, PAPEZOVA H, HANSIKOVA H, WENCHICH L, ZEMAN J: Activities of respiratory chain complexes in isolated platelets in females with anorexia nervosa. Int J Eat Disord 40: 659-663, 2007.

BOLEA I, GELLA A, UNZETA M. Propargylamine-derived multitarget-directed ligands: fighting Alzheimer's disease with monoamine oxidase inhibitors. J Neural Transm (Vienna) 120: 893-902, 2013.

BOSETTI F, BRIZZI F, BAROGI S, MANCUSO M, SICILIANO G, TENDI EA, MURRI L, RAPOPORT SI, SOLAINI G: Cytochrome $\mathrm{c}$ oxidase and mitochondrial $\mathrm{F}_{1} \mathrm{~F}_{0}$-ATPase (ATP synthase) activities in platelets and brain from patients with Alzheimer's disease. Neurobiol Aging 23: 371-376, 2002.

BUKKAPATNAM RN, GABLER NB, LEWIS WR: Statins for primary prevention of cardiovascular mortality in women: a systematic review and meta-analysis. Prev Cardiol 13: 84-90, 2010.

CARDOSO SM, PROENÇA MT, SANTOS S, SANTANA I, OLIVEIRA CR: Cytochrome $c$ oxidase is decreased in Alzheimer's disease platelets. Neurobiol Aging 25: 105-110, 2004.

CASOLI T, BALIETTI M, GIORGETTI B, SOLAZZI M, SCARPINO O, FATTORETTI P: Platelets in Alzheimer's disease-associated cellular senescence and inflammation. Curr Pharm Des 19: 1727-1738, 2013.

CHATTERJEE S, KRISHNAMOORTHY P, RANJAN P, ROY A, CHAKRABORTY A, SABHARWAL MS, RO R, AGARWAL V, SARDAR P, DANIK J, GIRI JS, DEGOMA EM, KUMBHANI DJ: Statins and cognitive function: an updated review. Curr Cardiol Rep 17: 4, 2015.

CHEN M, INESTROSA NC, ROSS GS, FERNANDEZ HL: Platelets are the primary source of amyloid $\beta$-peptide in human blood. Biochem Biophys Res Commun 213: 96-103, 1995.

DA PRADA M, CESURA AM, LAUNAY JM, RICHARDS JG: Platelets as a model for neurones? Experientia 44: 115-126, 1988.

DEICHMANN R, LAVIE C, ANDREWS S: Coenzyme $\mathrm{Q}_{10}$ and statin-induced mitochondrial dysfunction. Ochsner $J$ 10: $16-21,2010$.

DEMIERRE MF, HIGGINS PD, GRUBER SB, HAWK E, LIPPMAN SM: Statins and cancer prevention. Nat Rev Cancer 5: 930-942, 2005.

DESAI CS, MARTIN SS, BLUMENTHAL RS: Non-cardiovascular effects associated with statins. BMJ 349: g3743, 2014.

DONOVAN LE, DAMMER EB, DUONG DM, HANFELT JJ, LEVEY AI, SEYFRIED NT, LAH JJ: Exploring the potential of the platelet membrane proteome as a source of peripheral biomarkers for Alzheimer's disease. Alzheimers Res Ther 5: 32, 2013.

FELDMAN HH, DOODY RS, KIVIPELTO M, SPARKS DL, WATERS DD, JONES RW, SCHWAM E, SCHINDLER R, HEY-HADAVI J, DEMICCO DA, BREAZNA A; LEADE INVESTIGATORS: Randomized controlled trial of atorvastatin in mild to moderate Alzheimer disease: LEADe. Neurology 74: 956-964, 2010.

FIŠAR Z, HROUDOVÁ J, HANSÍKOVÁ H, SPÁČILOVÁ J, LELKOVÁ P, WENCHICH L, JIRÁK R, ZVĚŘOVÁ M, ZEMAN J, MARTÁSEK P, RABOCH J: Mitochondrial respiration in the platelets of patients with Alzheimer's disease. Curr Alzheimer Res 13: 930-941, 2016.

FRANCO D, FRANCO T, SCHETTINO AM, FILHO JM, VENDRAMIN FS: Protocol for obtaining platelet-rich plasma (PRP), platelet-poor plasma (PPP), and thrombin for autologous use. Aesthetic Plast Surg 36: 1254-1259, 2012. 
GALTIER F, MURA T, RAYNAUD DE MAUVERGER E, CHEVASSUS H, FARRET A, GAGNOL JP, COSTA F, DUPUY A, PETIT P, CRISTOL JP, MERCIER J, LACAMPAGNE A: Effect of a high dose of simvastatin on muscle mitochondrial metabolism and calcium signaling in healthy volunteers. Toxicol Appl Pharmacol 263: 281-286, 2012.

GAZZERRO P, PROTO MC, GANGEMI G, MALFITANO AM, CIAGLIA E, PISANTI S, SANTORO A, LAEZZA C, BIFULCO M: Pharmacological actions of statins: a critical appraisal in the management of cancer. Pharmacol Rev 64: 102-146, 2012.

GNAIGER E, KUZNETSOV AV, SCHNEEBERGER S, SEILER R, BRANDACHER G, STEURER W, MARGREITER R: Mitochondria in the cold. In: Life in the Cold. HELDMAIER G, KLINGENSPOR M (eds), Springer, New York, 2000, pp 431-442.

GNAIGER E: Mitochondrial pathways and respiratory control. An introduction to OXPHOS analysis. 4th ed. Mitochondr Physiol Network 19.12. OROBOROS MiPNet Publications, Innsbruck, 2014, 80 pp. Open Access: www.bioblast.at/index.php/Gnaiger_2014_MitoPathways

GOLOMB BA, EVANS MA: Statin adverse effects: a review of the literature and evidence for a mitochondrial mechanism. Am J Cardiovasc Drugs 8: 373-418, 2008.

HAUPTMANN S, KEIL U, SCHERPING I, BONERT A, ECKERT A, MÜLLER WE: Mitochondrial dysfunction in sporadic and genetic Alzheimer's disease. Exp Gerontol 41: 668-673, 2006.

HOFFMAN KB, KRAUS C, DIMBIL M, GOLOMB BA: A survey of the FDA's AERS database regarding muscle and tendon adverse events linked to the statin drug class. PLoS One 7: e42866, 2012.

HROUDOVÁ J, FIŠAR Z, KITZLEROVÁ E, ZVĚŘOVÁ M, RABOCH J: Mitochondrial respiration in blood platelets of depressive patients. Mitochondrion 13: 795-800, 2013.

KALRA J, KHAN A: Reducing A $\beta$ load and tau phosphorylation: Emerging perspective for treating Alzheimer's disease. Eur J Pharmacol 764: 571-581, 2015.

KANEEZ FS, SAEED SA: Investigating GABA and its function in platelets as compared to neurons. Platelets 20: 328-333, 2009.

KAUFMANN P, TÖRÖK M, ZAHNO A, WALDHAUSER KM, BRECHT K, KRÄHENBÜHL S: Toxicity of statins on rat skeletal muscle mitochondria. Cell Mol Life Sci 63: 2415-2425, 2006.

KRIGE D, CARROLL MT, COOPER JM, MARSDEN CD, SCHAPIRA AH: Platelet mitochondrial function in Parkinson's disease. The Royal Kings and Queens Parkinson Disease Research Group. Ann Neurol 32: 782-788, 1992.

LA GUARDIA PG, ALBERICI LC, RAVAGNANI FG, CATHARINO RR, VERCESI AE: Protection of rat skeletal muscle fibers by either L-carnitine or coenzyme Q10 against statins toxicity mediated by mitochondrial reactive oxygen generation. Front Physiol 4: 103, 2013.

LARSEN S, STRIDE N, HEY-MOGENSEN M, HANSEN CN, BANG LE, BUNDGAARD H, NIELSEN LB, HELGE JW, DELA F: Simvastatin effects on skeletal muscle: relation to decreased mitochondrial function and glucose intolerance. J Am Coll Cardiol 61: 44-53, 2013.

LENAZ G, D'AURELIO M, MERLO PICH M, GENOVA ML, VENTURA B, BOVINA C, FORMIGGINI G, PARENTI CASTELLI G: Mitochondrial bioenergetics in aging. Biochim Biophys Acta 1459: 397-404, 2000.

LI Q, ZHUANG QK, YANG JN, ZHANG YY: Statins excert neuroprotection on cerebral ischemia independent of their lipid-lowering action: the potential molecular mechanisms. Eur Rev Med Pharmacol Sci 18: 1113-1126, 2014.

LIM YA, GRIMM A, GIESE M, MENSAH-NYAGAN AG, VILLAFRANCA JE, ITTNER LM, ECKERT A, GÖTZ J: Inhibition of the mitochondrial enzyme ABAD restores the amyloid- $\beta$-mediated deregulation of estradiol. PLoS One 6: e28887, 2011.

LLOYD SM, STOTT DJ, DE CRAEN AJ, KEARNEY PM, SATTAR N, PERRY I, PACKARD CJ, BRIGGS A, MARCHBANK L, COMBER H, JUKEMA JW, WESTENDORP RG, TROMPET S, BUCKLEY BM, FORD I: Long-term effects of statin treatment in elderly people: extended follow-up of the PROspective Study of Pravastatin in the Elderly at Risk (PROSPER). PLoS One 8: e72642, 2013. 
MAES M, FIŠAR Z, MEDINA M, SCAPAGNINI G, NOWAK G, BERK M: New drug targets in depression: inflammatory, cell-mediated immune, oxidative and nitrosative stress, mitochondrial, antioxidant, and neuroprogressive pathways. And new drug candidates-Nrf2 activators and GSK-3 inhibitors. Inflammopharmacology 20: 127-150, 2012.

MALFITANO AM, MARASCO G, PROTO MC, LAEZZA C, GAZZERRO P, BIFULCO M: Statins in neurological disorders: an overview and update. Pharmacol Res 88: 74-83, 2014.

MARZILLI M: Pleiotropic effects of statins: evidence for benefits beyond LDL-cholesterol lowering. Am J Cardiovasc Drugs 10: 3-9, 2010.

MCGUINNESS B, CRAIG D, BULLOCK R, PASSMORE P: Statins for the prevention of dementia. Cochrane Database Syst Rev 1: CD003160, 2016.

MENDELSON SD: The current status of the platelet 5-HT $2 \mathrm{~A}$ receptor in depression. J Affect Disord 57: 13-24, 2000.

MERCADO CP, KILIC F: Molecular mechanisms of SERT in platelets: regulation of plasma serotonin levels. Mol Interv 10: 231-241, 2010.

MERLO PICH M, BOVINA C, FORMIGGINI G, COMETTI GG, GHELLI A, PARENTI CASTELLI G, GENOVA ML, MARCHETTI M, SEMERARO S, LENAZ G: Inhibitor sensitivity of respiratory complex I in human platelets: a possible biomarker of ageing. FEBS Lett 380: 176-178, 1996.

MOHAMMADI-BARDBORI A, NAJIBI A, AMIRZADEGAN N, GHARIBI R, DASHTI A, OMIDI M, SAEEDI A, GHAFARIAN-BAHREMAN A, NIKNAHAD H: Coenzyme Q10 remarkably improves the bio-energetic function of rat liver mitochondria treated with statins. Eur J Pharmacol 762: 270-274, 2015.

MORRELL CN, AGGREY AA, CHAPMAN LM, MODJESKI KL: Emerging roles for platelets as immune and inflammatory cells. Blood 123: 2759-2767, 2014.

NACI H, BRUGTS J, ADES T: Comparative tolerability and harms of individual statins: a study-level network metaanalysis of 246955 participants from 135 randomized, controlled trials. Circ Cardiovasc Qual Outcomes 6: 390-399, 2013.

NADANACIVA S, DYKENS JA, BERNAL A, CAPALDI RA, WILL Y: Mitochondrial impairment by PPAR agonists and statins identified via immunocaptured OXPHOS complex activities and respiration. Toxicol Appl Pharmacol 223: 277-287, 2007.

OTT BR, DAIELLO LA, DAHABREH IJ, SPRINGATE BA, BIXBY K, MURALI M, TRIKALINOS TA: Do statins impair cognition? A systematic review and meta-analysis of randomized controlled trials. J Gen Intern Med 30: 348-358, 2015.

PADALA KP, PADALA PR, MCNEILLY DP, GESKE JA, SULLIVAN DH, POTTER JF: The effect of HMG-CoA reductase inhibitors on cognition in patients with Alzheimer's dementia: a prospective withdrawal and rechallenge pilot study. Am J Geriatr Pharmacother 10: 296-302, 2012.

PARIHAR A, PARIHAR MS, ZENEBE WJ, GHAFOURIFAR P: Statins lower calcium-induced oxidative stress in isolated mitochondria. Hum Exp Toxicol 31: 355-363, 2012.

PESTA D, GNAIGER E: High-resolution respirometry: OXPHOS protocols for human cells and permeabilized fibers from small biopsies of human muscle. Methods Mol Biol 810: 25-58, 2012.

PLÁTENÍK J, FIŠAR Z, BUCHAL R, JIRÁK R, KITZLEROVÁ E, ZVĚŘOVÁ M, RABOCH J: GSK3 $\beta$, CREB, and BDNF in peripheral blood of patients with Alzheimer's disease and depression. Prog Neuropsychopharmacol Biol Psychiatry 50: 83-93, 2014.

RAY KK, SESHASAI SR, ERQOU S, SEVER P, JUKEMA JW, FORD I, SATTAR N: Statins and all-cause mortality in high-risk primary prevention: a meta-analysis of 11 randomized controlled trials involving 65,229 participants. Arch Intern Med 170: 1024-1031, 2010.

RUSCICA M, MACCHI C, MORLOTTI B, SIRTORI CR, MAGNI P: Statin therapy and related risk of new-onset type 2 diabetes mellitus. Eur J Intern Med 25: 401-406, 2014.

SATHASIVAM S: Statin induced myotoxicity. Eur J Intern Med 23: 317-324, 2012.

SHAD KF, SAEED SA: The metabolism of serotonin in neuronal cells in culture and platelets. Exp Brain Res 183: 411-416, 2007.

SHEPARDSON NE, SHANKAR GM, SELKOE DJ: Cholesterol level and statin use in Alzheimer disease: I. Review of epidemiological and preclinical studies. Arch Neurol 68: 1239-1244, 2011. 
SHI C, GUO K, YEW DT, YAO Z, FORSTER EL, WANG H, XU J: Effects of ageing and Alzheimer's disease on mitochondrial function of human platelets. Exp Gerontol 43: 589-594, 2008.

SIRVENT P, FABRE O, BORDENAVE S, HILLAIRE-BUYS D, RAYNAUD DE MAUVERGER E, LACAMPAGNE A, MERCIER J: Muscle mitochondrial metabolism and calcium signaling impairment in patients treated with statins. Toxicol Appl Pharmacol 259: 263-268, 2012.

SJÖVALL F, EHINGER JK, MARELSSON SE, MOROTA S, FROSTNER EA, UCHINO H, LUNDGREN J, ARNBJÖRNSSON E, HANSSON MJ, FELLMAN V, ELMÉR E: Mitochondrial respiration in human viable platelets-methodology and influence of gender, age and storage. Mitochondrion 13: 7-14, 2013.

SJÖVALL F, MOROTA S, HANSSON MJ, FRIBERG H, GNAIGER E, ELMÉR E: Temporal increase of platelet mitochondrial respiration is negatively associated with clinical outcome in patients with sepsis. Crit Care 14: R214, 2010.

TAYLOR F, HUFFMAN MD, MACEDO AF, MOORE TH, BURKE M, DAVEY SMITH G, WARD K, EBRAHIM S: Statins for the primary prevention of cardiovascular disease. Cochrane Database Syst Rev 1: CD004816, 2013.

VALENTI R, PANTONI L, MARKUS HS: Treatment of vascular risk factors in patients with a diagnosis of Alzheimer's disease: a systematic review. BMC Med 12: 160, 2014.

VALLA J, SCHNEIDER L, NIEDZIELKO T, COON KD, CASELLI R, SABBAGH MN, AHERN GL, BAXTER L, ALEXANDER G, WALKER DG, REIMAN EM: Impaired platelet mitochondrial activity in Alzheimer's disease and mild cognitive impairment. Mitochondrion 6: 323-330, 2006.

VAUGHAN RA, GARCIA-SMITH R, BISOFFI M, CONN CA, TRUJILLO KA: Ubiquinol rescues simvastatinsuppression of mitochondrial content, function and metabolism: Implications for statin-induced rhabdomyolysis. Eur J Pharmacol 711: 1-9, 2013.

VEVERA J, FIŠAR Z, KVASNIČKA T, ZDENĚK H, STÁRKOVÁ L, ČEŠKA R, PAPEŽOVÁ H: Cholesterollowering therapy evokes time-limited changes in serotonergic transmission. Psychiatry Res 133: 197-203, 2005.

VEVERA J, VALEŠ K, FIŠAR Z, HROUDOVÁ J, SINGH N, STUCHLÍK A, KAČER P, NEKOVÁŘOVÁ T: The effect of prolonged simvastatin application on serotonin uptake, membrane microviscosity and behavioral changes in the animal model. Physiol Behav 158: 112-120, 2016.

XIE Y, DENG S, CHEN Z, YAN S, LANDRY DW: Identification of small-molecule inhibitors of the A $\beta$-ABAD interaction. Bioorg Med Chem Lett 16: 4657-4660, 2006.

XU J, SHI C, LI Q, WU J, FORSTER EL, YEW DT: Mitochondrial dysfunction in platelets and hippocampi of senescence-accelerated mice. J Bioenerg Biomembr 39: 195-202, 2007.

YOUDIM MB: Platelet monoamine oxidase B: use and misuse. Experientia 44: 137-141, 1988.

YU X, PAN Y, MA H, LI W: Simvastatin inhibits proliferation and induces apoptosis in human lung cancer cells. Oncol Res 20: 351-357, 2013.

YUBERO-LAHOZ S, ROBLEDO P, FARRÉ M, DE LATORRE R: Platelet SERT as a peripheral biomarker of serotonergic neurotransmission in the central nervous system. Curr Med Chem 20: 1382-1396, 2013.

ZHAO Z, CUI W, ZHANG H, GAO H, LI X, WANG Y, HU H, LI B: Pre-treatment of a single high-dose of atorvastatin provided cardioprotection in different ischaemia/reperfusion models via activating mitochondrial KATP channel. Eur J Pharmacol 751: 89-98, 2015. 